\title{
DINAMIKA SOSIAL BUDAYA MASYARAKAT MELAYU PESISIR (Studi Pengelolaan Madu Sialang di Desa Rawa Mekar J aya)
}

\author{
T. Romi Marnelly ${ }^{1}$

\begin{abstract}
All societies experience the change. But also with the society that is in the village of Rawa Mekar J aya, Subdistrict of Sungai Apit, Regency of Siak. Here, there is unique tradition that is called menumbai interrelated the use of sialang's honey bee. Together with the age development, this tradition starts to have dynamics. So that the questions come 1) What kind of aspects that experience the cultural social change in the processing activity of sialang's honey bee in the village of Rawa Mekar J aya Then, what kind of factors that push that change?. The research method that is used is descriptive qualitative. The location election in the village of Rawa Mekar J aya because this location has sialang's tree and the activity that is involved with the sialang's honey. The research subject consists of the village chief, society figure, owner of sialang trunk and sialang's trunk climber. The Data Collecting Technics are such as observation and deep interview. The sampling technic is namly purposive sampling. Based on the research result, it can be known that the aspects that experience the change in the processing activity of sialang's honey is aspect of language, knowledge, tools and life equipment, economy system and religion system. Meanwhile, the factors that push the change is the contact with another culture, unsatisfication of society towards certain life sectors, future orientation and value that the human should struggle to fix the life.
\end{abstract}

Keywords: the change, cultural, social, honey, Sialang

\begin{abstract}
Abstrak
Tidak ada masyarakat yang tidak mengalami perubahan. Begitu juga dengan masyarakat yang berada di Desa Rawa Mekar J aya Kec. Sungai Apit Kab. Siak. Disini terdapat tradisi unik yang disebut menumbai terkait pemanfaatan lebah madu sialang. Seiring perkembangan zaman, tradisi ini mulai berdinamika. Sehingga memunculkan pertanyaan 1) Apa saja aspek-aspek yang mengalami perubahan sosial budaya pada aktivitas penegelolaan lebah madu sialang di Kampung Rawa Mekar Jaya? Lalu, faktor-faktor apa saja yang mendorong terjadinya perubahan tersebut?. Metode penelitian yang digunakan adalah kualitatif deskriptif. Pemilihan lokasi di Kampung Rawa Mekar J aya karena lokasi ini terdapat Pohon sialang dan aktivitas yang berkaitan dengan madu sialang. Subjek penelitian terdiri dari penghulu kampung, tokoh masyarakat, pemilik batang sialang dan pemanjat batang sialang. Teknik Pengumpulan Data berupa observasi, dan wawancara mendalam. Teknik pengambilan sampel yakni purposive sampling. Berdasarkan hasil penelitian, dapat diketahui aspek-aspek yang mengalami perubahan dalam aktivitas pengelolaan madu sialang adalah aspek bahasa, pengetahuan, peralatan dan perlengkapan hidup, sistem konomi serta sistem religi. Sedangkan faktor-faktor yang mendorong terjadinya perubahan adalah kontak dengan budaya lain, ketidakpuasan masyarakat terhadap bidang-bidang kehidupan tertentu, orientasi masa depan dan nilai bahwa manusia harus senantiasa berikhtiar untuk memperbaiki hidupnya.
\end{abstract}

Kata-kata Kunci: perubahan, sosial, budaya, madu, Sialang

\footnotetext{
${ }^{1}$ Penulis adalah dosen Jurusan Sosiologi FISIP Universitas Riau, Email: tengkuromimarnelly@gmail.com
} 


\section{A. PENDAHULUAN}

I ndonesia adalah bangsa yang besar, yang kaya akan budaya. Hilden Gert menyebutkan bahwa wilayah Indonesia ini terdiri dari beribu-ribu pulau yang didiami oleh beranekaragam suku bangsa yang merupakan golongan etnik dan mengunakan lebih kurang 250 bahasa daerah serta memiliki berbagai kepercayaan dan kebudayaan yang beranekaragam (Nasikun, 1974:31). Selain kaya akan budaya, Indonesia juga memiliki kekayaan alam yang berlimpah. Dimana tiap-tiap daerah memiliki ciri khas hasil alam yang menjadi icon sebuah kota, misalya Kota Malang terkenal dengan buah Apelnya, Kota Palembang dengan buah Dukunya, Kalimantan dengan Duriannya, dan lain sebagainya, begitu juga dengan Riau yang terkenal dengan madu sialangnya.

Berjarak sekitar 120 Kilometer dari ibu kota Propinsi Riau. Terdapat sebuah Desa yang bernama Rawa Mekar Jaya yakni sebuah desa atau kampung istilah masyarakat setempat, yang berada di pesisir Provinsi Riau tepatnya di Kecamatan Sungai Apit, Kabupaten Siak. Kampung Rawa Mekar Jaya sesuai dengan namanya "Rawa" adalah wilayah yang didominasi oleh tanah gambut gambut dengan topografi dataran rendah. Kedalaman gambut bervariasi antara 2 sampai 8 meter dan berada pada ketinggian tanah antara 5-7 meter dari permukaan laut. Luas kampung ini diperkirakan sekitar 15.752 hektar dengan rincian 600 hektar pemukiman masyarakat, 4.000 hektar perkebunan masyarakat, 2.500 hektar hutan tanam industri, 3.120 hektar taman nasional danau zamrud dan jumlah hutan yang diperkirakan lebih kurang sebanyak 5.532 hektar. (Kantor Desa Rawa Mekar Jaya, 2017)

Kampung Rawa Mekar Jaya berada di Pesisir Sungai Rawa ini merupakan aliran dari air danau Taman Nasional Zamrud di Desa Dayun Kecamatan Dayun. Keaneka ragaman tumbuh-tumbuhan yang di Kampung Rawa Mekar Jaya sangat bervariasi, namun ada salah satu pohon mempunyai keunikan dan menjadi tumpuan mata pencaharian masyarakat yang ada disekitarnya yaitu Pohon Sialang.

Pohon Lebah Madu Sialang menja dikan misteri bagi masyarakat yang berada disekitarnya. Sehingga kegiatan masyarakat dalam mengambil sumber daya alam di hutan yang satu ini merupakan sesuatu yang amat sakral. Pohon Sialang bukanlah jenis atau nama pohon yang disebut sialang. Pohon yang di hinggapi oleh Lebah Madu disebut dengan pohon Sialang, jadi pohon sialang dapat berupa pohon besar yang sangat tinggi dan sukar untuk di jangkau oleh jenis binatang seperti Beruang Madu dan Jenisnya yang memakan madu. Pohon yang di hinggapi oleh lebah biasanya berupa jenis pohon: a) Pohon Kempas; b) Pohon Beringin; c) Pohon Pulai; d) Pohon Punak; e) Pohon Meranti. Pohon-pohon tersebut tingginya tidak kurang dari 50 meter dengan ketingggian lurus dan berdiameter paling kurang $500 \mathrm{Cm}$. Sehingga pohon tersebut sangat kokoh dan apa bila terjadi angin ribut yang kencang maka tidak terjadi kegoncangan yang berarti. Kekokohan pohon sialang ini mengakibatkan kenyama nan lebah madu yang bersarang. (Kantor Desa Rawa Mekar Jaya, 2017).

Masyarakat adalah orang yang hidup bersama yang menghasilkan kebudayan. Dengan demikian tanpa adanya masyarakat sebagai wadah tumbuh kembangnya budaya maka kebudayaan tidak akan ada. Menurut Koentjaraningrat, unsur-unsur kebudayaan adalah (a) peralatan dan perlengkapan hidup manusia sehari-hari; (b) sistem mata pencaharian dan sistem ekonomi; (c) sistem kemasyarakatan; (d) bahasa sebagai media komunikasi, bahasa lisan dan tulisan; (e) ilmu pengetahuan dan kesian dan (f) sistem religi (Abidin dan Saebani, 2014 : 69).

Kehidupan manusia akan selalu mengalami perubahan, tidak ada masya rakat yang benar-benar statis. Sebab kehidupan sosial adalah dinamis. (Setiadi dan Kolip, 2011: 610). Kehidupan adalah gerakan dan perubahan, maka bila berhenti berarti tidak ada lagi kehidupan melainkan merupakan suatu keadaan yang sama sekali berbeda yang dsebut ketiadaan atau kematian. (Sztompka, 2017:9). Perubahanperubahan itu dapat berupa mencolok, ada pula yang berjalan sangat cepat bahkan ada pula yang berjalan sangat lambat (Soemardjan dan Soemardi, 1974:78).

Berbicara masalah lingkungan, paling tidak dikenal dua konsep tentang lingkungan yaitu; geofisik dan biofisik. Contoh geofisik 
misalnya; air, tanah, batu-batuan dan sebagainya. Sedangkan biofisik termasuk di dalamnya seperti: tumbuh-tumbuhan, jasad renik, hewan dan manusia itu sendiri. Dari dua konsep lingkungan itu, manusia adalah sentral dari seluruh ritme kehidupan alam ini, dimana manusia mampu mengontrol, merubah dan mempertahankan lingkunga nnya (baik geofisik maupun biofisik) untuk kepentingan hidupnya. Oleh sebab itu, untuk memahami hubungan timbal balik antara manusia dan lingkungannya itu maka harus selalu melihat dari segi kepentingan manusia yang hidup di dalam lingkungan tertentu itu. artinya, bahwa manusia itu hidupnya sangat terkait dan dipengaruhi oleh lingkungan dan faktor-faktor lain yang cukup dominan yang memberi arah dan pedoman bagi manusai untuk berperilaku. (Hidir, 2009:43).

Manusia, lingkungan dan kebudayaan, merupakan satu kesatuan sistem yang jalin menjalin satu sama lain. Ketika satu komponen dari sistem mengalami perubahan maka komponen yang lainnya juga akan mengalami perubahan. Masya rakat Kampung Mekar Rawa Jaya adalah masyarakat yang bersahabat dan bersebati dengan alam. Di dalam mengambil hasilhasil alam terutama madu sialang terdapat serangkaian acara yang harus dilakukan yang disebutkan juga dengan tradisi menumbai.yang syarat dengan nuansa sakral. Perlahan tapi pasti seiring perkembangan zaman tradisi ini mulai mengalami perubahan.

Berdasarkan latar belakang di atas maka masalah yang dapat dirumuskan dalam penelitian ini adalah: 1) Apa saja aspek-aspek yang mengalami perubahan sosial budaya pada aktivitas penegelolaan lebah madu sialang di Kampung Rawa Mekar Jaya? Selanjutnya faktor-faktor apa saja yang mendorong terjadinya perubahan pada aktivitas pengelolaan lebah madu sialang tersebut?

\section{B. METODE PENELITIAN}

$\mathrm{M}$ etode penelitian yang digunakan adalah secara kualitatif deskriptif melalui reduksi data, penyajian data dan pengambilan kesimpulan dengan pendekatan fenomenologi dimana peneliti akan melakukan wawancara mendalam yang kemudian hasilnya akan diolah dan interpretasikan untuk dianalisis lebih lanjut dengan menggunakan perspekstif sosio logis. Lokasi Penelitian ditetapkan di Kampung Rawa Mekar Jaya Kecamatan Sungai Apit Kabupaten Siak Provinsi Riau karena lokasi ini terdapatnya Pohon sialang dan aktivitas yang berkaitan dengan madu sialang. Subjek penelitian terdiri dari penghulu kampung, tokoh masyarakat, pemilik batang saialang dan pemanjat batang sialang. Teknik Pengumpulan Data berupa observasi, selanjutnya melakukan wawancara dengan key informan ynng mengetahui seluk beluk lebah madu sialang serta tradisi menumbai. Teknik pengambilan sampel yakni purposve sampling. Informasi dan data awal yang diperoleh kemudian dikonfimasi dengan informan lainnya sehingga keabsahan data dan informasi dapat dipertanggungjawabkan kebenaran nya.

\section{HASIL PENELITIAN}

\section{Perubahan Sosial Budaya dalam Aktivitas Pengelolaan Lebah Madu Sialang}

$\mathrm{M}$ erangkum pemikiran Sztompka (2017) jika ingin mengakaji masalah perubahan, maka ada hal-hal yang perlu diamati, apakah memang ada hal yang berubah, lalu bagaimana perubahan itu dari suatu jangka waktu dengan waktu yang lainnya, dan perubahan itu tentu saja pada sistem sosial yang sama. Ada tiga hal yang mendasari perubahan sosial yakni apakah terdapat hal-hal yang membedakan

Dalam penelitian ini ditemukan bahwa aktivitas masyarakat dalam mengelola madu sialang telah mengalami perubahan. Waktu perubahahan dilihat sebelum tahun 2002 dimana masyarakat masih melakukan tradisi menumbai. Lalu, mulai tahun 2002 sampai sekarang 2017, kegiatan menumbai sudah mulai ditinggalkan. Pra dan pasca tahun 2002 inilah akan terlihat beberapa perbe daan pada aktivitas pengolahan madu pada Masyarakat Kampung Mekar Rawa Jaya tersebut.

Menurut Kluckhon ada 7 kebudayaan yang bersifat universal yakni pertama, yang mencakup peralatan dan perlengakapan hidup misalnya dalam hal ini adalah peralatan dan perlengakapan mengambil 
madu, kedua terkait aspek ekonomi misalnya mata pencaharian dan sistem ekonomi, ketiga dalah sistem kamsyara katan, kempat aspek linguistik, kelima terkait seni, keenam mencakup aspek pengeta huan dan ketujuh terkait religious system (Soekanto, 2013). Berikut beberapa aspek yang mengalami perubahan dalam aktivitas pengolahan madu sialang:

\section{Aspek Bahasa}

Dulunya aktivitas ini oleh masyarakat setempat disebut sebagai menumbai. Namun, kata menumbai dalam masyarakat kampung Rawa Mekar Jaya ini sudah jarang digunakan. Masyakat hanya menyebutkan sebagai mengambek madu. Selanjutnya bahasa yang mengalami perubahan yakni pada tradisi menumbai dalam menurunkan madu dari atas pohon sialang adalah dengan Menggunakan kode panggilan kerena tidak terlihat dari atas dan tidak boleh menyebutkan nama. Karena jika menyebut nama masyarakat mempercayai orang yang disebutkan namanya tersebut akan mendapat celaka diganggu oleh makhluk penunggu hutan. Saat sekarang ini bahasa yang digunakan dalam proses menurunkan madu adalah kata tarik, ulur, sambut dengan intonasi yang jelas.

\section{Aspek Pengetahuan}

Dalam tradisi menumbai, aktivitas memanen madu dilakukan pada malam hari. Hal ini dilakukan karena masyarakat mem percayai bahwa lebah tidak akan menyengat jika dilakukan pada waktu tersebut. Namun, saat sekarang ini panen madu sialang pada umumnya dilakukan pada siang hari.

Madu yang dipanen di atas Pohon sialang, dulunya mereka mengambil semua nya. Sekarang mereka meninngalkan sambang ratu atau rumah ratu. Agar lebah tetap memproduksi madu secara berkelan jutan di pohon yang sama. Sehingga hasilnya dapat dinikmati secara terus menerus.

\section{Aspek Peralatan dan Perlengkapan}

Pohon sialang dulunya dipanjat tanpa menggunakan pengaman tali seperti sekarang ini. Karena masyarakat memper cayai bahwa dengan mantra yang dituturkan oleh pawang sudah cukup memberikan rasa aman. Selain itu, masyarakat tidak menggunakan tali disebabkan mereka belum menemukan cara yang baik dalam memanjat atau belum terpikirkan menggu nakan tali. Saat ini, selain tali alat pengaman yang penting adalah pakaian pelindung berupa jaket atau pakaian yang belengan panjang, celana panjang, sarung tangan dan penutup muka untuk melindugi diri dari sengatan lebah. Dahulunya para pemnajat tidak menngunakan baju, bahkan celana pendek saja. Agar terhindar dari sengatan lebah mereka melumuri tubuhnya dengan minyak kelapa.

Cara-cara yang dilakukan untuk mengusir lebah agar tidak menyengat dulunya masyarakat menggunakan andang (sabut kelapa dan daun kelapa kering) yang dibakar. Namun sekarang sama sekali tidak digunakan dengan alasan takut bunga api memicu kebakaran hutan dan mencelakai lebah

\section{Aspek Sistem Religi}

Sebelum memanjat pohon sialang, para pengelola madu yang dipimpin oleh tuan sialang untuk membacakan mantra-mantra yang ditujukan kepada makhluk-makluk penungu hutan agar tidak mengganggu proses pemanenan madu. Pada prosesi menumbai ini, mereka juga memberikan semah berupa pulut kuning, air bunga, bertih, renjis air daun pandan wangi, dan membakar kemenyan Sekarang mantra sudah ditingalkan dan diganti dengan doa berupa ayat-ayat suci Alquran yang dibacakan oleh si pemanjat dan tidak lagi memberikan semah atau sesajen.

\section{Aspek Sistem Ekonomi}

Madu yang sudah dipanen dulunya dijual dalam bentuk cairan madu yang sudah dipisah dari sambangnya. Sekarang madu dijual sekaligus dengan sambangnya. Ini bertujuan menunjukkan keaslian dari madu yang dijual karena saat ini sangat banyak sekali madu yang dicampur dengan air dan gula are, sehingga keaslian madu diragukan. Dulunya madu ini diperah atau dipisahkan dari sambangnya secara lang sung di lokasi pengambilan madu. Saat ini madu dimasukkan dalam plastik dan tidak diperah dengan alasan untuk menjaga keaslian dan kebersihan madu.

Mengenai pola pembagian hasil dulunya tiap-tiap orang yang ikut daam 
pelaksanaan menumbai itu langsung mem peroleh madu. Saat sekarang ini, bentuk bagi hasil bukan berupa madu nya tetapi berupa uang ketika madu itu sudah dijual kepada bos madu.

2. Faktor-faktor pendorong perubahan sosial budaya aktivitas pengelolaan Lebah Madu Sialang

$\mathrm{D}$ alam masyarakat dimana terjadi suatu proses perubahan, terdapat faktor-faktor yang mendorong jalannya perubahan yang terjadi. Faktorfaktor tersebut antara lain sebagai berikut : 1) Kontak dengan budaya lain 2) sistem pendidikan formal yang maju 3) sikap menghargai hasil karya seseorang dan keinginan-keinginan untuk maju; 4) toleransi terhadap perbuatan-perbuatan yang menyim pang (deviation), yang bukan merupakan delik; 5) sistem terbuka lapisan masyarakat; 6) penduduk yang heterogen; 7) ketidak puasan masysarakat terhadap bidangbidang kehidupan tertentu 8) orientasi ke masa depan; 9) nilai bahwa manusia harus senantiasa berihtiar unntuk memperbaiki hidupnya (Soekanto, 2013 : 283-286).

Menurut Kontjaraningrat (1990), pene muan baru dalam masyarakat pesisir didorong oleh kreativitas yang tumbuh karena:

a) Kesadaran para individu akan adanya kekurangan-kekurangan dalam kebudayaan mereka

b) Adanya kesadaran akan pentingnya mutu keahlian yang bersangkutan, sehingga yang telah ahli dalam suatu bidang akan terus meningkatkan keahliannya

c) Adanya sistem perangsang dalam masyarakat yang mendorong mutu, seperti kehoramtan, kedudukan, harta

d) Adanya krisis dalam masyarakat, yag berarti bahwa dalam masyarakat itu ada sejumlah orang yang menentang keadaan karena mereka sadar akan kekurangan-kekurangan yang ada dalam masyarakat itu serta merasa tidak puas dengan keadaan itu (dalam Satria, $2015:$ 57)

Berdasarkan hasil penelitian, ditemu kan beberapa faktor yang mendorong perubahan sosial budaya pada aktivitas pengolahan madu sialang di Kampung
Mekar Rawa Jaya dapat dirinci sebagai berikut:

\section{Kontak dengan budaya lain}

Terjadinya perubahan pada aktivitas pengelohan madu sialang adalah karena proses difusi. Difusi merupakan penyebaran unsur-unsur kebudayaan dari individu kepada individu lainnya. Dengan terjadinya difusi, penemuan baru yang sudah diterima oleh masyarakat dapat disebarkan kepada masyarakat luas. Penggunaan tali pengaman pada aktivitas memanjat pohon sialang, Menurut Key Informan adalah pertama kali diajarkan oleh pendatang yang berasal dari Lampung. Lalu, masyarakat Kampung Mekar Rawa Jaya mengadopsi unsur baru tersebut dan dilaksanakan sampai sekarang.

\section{Ketidakpuasan Masyarakat Terhadap Bidang-Bidang Kehidupan Tertentu}

Masyarakat tidak puas dengan tradisi lama dimana dalam menumbai proses pemanjatan sialang tidak menggunakan tali pengaman dan baju pelindung dan hanya mengandalkan mantra. Akibatnya, terjadilah human eror atau kecelakaan kerja karena kesalahan manusia misalnya jatuh dari pohon dan terkena sengatan lebah karena tidak menngunakan pakaian pelindung yang bisa saja mengancam jiwa bagi pengelola madu sialang ini.

\section{Orientasi Masa Depan}

Dulunya masyarakat dalam pengambi lan madu menggunakan api untuk mengusir lebah. Hal ini tentu saja tidak baik karena bisa saja menyebabkan terjadinya kebakaran hutan dan pada akhirnya mencelakai lebah sehingga lebah tidak lagi bersarang dipohon tersebut. Sekarang masyarakat sudah berpikir jauh kedepan bagaimana lebah madu sialang ini bisa terus berkembang dan terjaga, sehingga keberlangunag pohon sialang dan lebah madu terjamin bisa dinikmati oleh masyarakat kini hingga seterusnya.

\section{Nilai Bahwa Manusia Harus Senantiasa Berihtiar Unntuk Memper baiki Hidupnya}

Masyarakat Kampung Mekar Rawa Jaya punya pepatah bahwa hari ini harus lebih baik dari hari kemarin. ini menunjukkan 
bahwa masyarakat senantiasa berusaha agar kehidupan mereka menjadi semakin baik dari hari ke harinya. Menjaga keamanan, menjaga keseimbangan lingku ngan, menjaga keaslian madu, menerapkan prinsip keadilan dalam pembagian hasil, menunjukkan bahwa masyarakat berihtiar dalam memperbaiki hidupnya.

\section{KESIMPULAN}

spek-aspek yang mengalami peruba
han dalam aktivitas pengelolaan
madu sialang pada masyarakat
Kampung Mekar Rawa Jaya adalah aspek bahasa, aspek pengetahuan, aspek peralatan dan perlengkapan hidup, aspek sistem ekonomi dan aspek sistem religi. Sedangkan faktor-faktor yang mendorong terjadinya perubahan adalah terjadinya kontak dengan budaya lain, ketidakpuasan Masyarakat terhadap bidang-bidang kehidu pan tertentu, orientasi masa depan dan nilai bahwa manusia harus senantiasa berihtiar untuk memperbaiki hidupnya

\section{DAFTAR PUSTAKA}

Abidin, Yusuf Zainal dan Saebani, Beni Ahmad. 2014. Pengantar Sistem Sosial Budaya di Indonesia. Bandung. CV. Pustaka Setia.

Hidir, Ahmad. 2009. Antropologi Budaya, Perpektif Ekologi dan Perubahan Budaya. Pekanbaru . Unri Press.

Nasikun. 1974. Sistem Sosial Indonesia. Jakarta. Rajawali Press.

Ritzer, George \& Smart, Barry. 2011. Handbook Teori Sosial. Bandung. Nusa Media.

Ritzer, George. 2012. Teori Sosiologi dari Sosiologi Klasik sampai Perkembangan Terakhir Postmoder. Edisi kedelapan. Yogyakarta. Pustaka Pelajar.

Satria, Arif . 2015. Pengantar Sosiologi Masyarakat Pesisir. . Jakarta. Yayasan Pustaka Obor Indonesia

Setiadi, Elly M dan Kolip, Usman. 2011. Pengantar Sosiologi, Pemahaman Fakta dan Gejala Permasalahan Sosial : Teori, Aplikasi, dan Pemecahannya. Kencana Prenada Media Group. Jakarta

Soekanto, Soerjono. 2013. Sosiologi Suatu Pengantar. Jakarta. PT. Raja Grafindo Persada.

Soemardjan, Selo dan Soemardi, Soeleman. 1974. Jakarta. Setangkai Bunga Sosiologi. Felu.

Sztompka, Piötr.2017. Sosiologi Perubahan Sosial. Jakarta. Kencana. 